\title{
Comportamento variacionista da expressão pronominal a gente em textos escolares
}

\author{
Variationist behavior of pronominal expression we in school texts
}

\author{
Josenildo Barbosa Freire ${ }^{1}$
}

\begin{abstract}
Resumo: Há um número crescente de estudos que têm investigado a variação linguística. Resultados atestam que os usos linguísticos são condicionados por restrições internas quanto por sociais. Objetivamos descrever e analisar o comportamento da expressão pronominal "a gente", à luz da Teoria da Variação (LABOV, 1966; [1972] 2008) em textos escritos, produzidos por alunos de duas escolas da rede de ensino. O corpus é constituído por 91 textos (memórias literárias e crônicas) e está estratificado por sexo, nível de escolaridade, faixa etária, gênero textual/discursivo, tipo de escola e variáveis linguísticas. A metodologia seguiu os passos da técnica laboviana e para tratamento estatístico, após a extração das ocorrências e codificação, foi utilizado o Programa do Goldvarb X (SANKOFF, TAGLIAMONTE; SMITH, 2005). Os resultados demonstram que a expressão pronominal "a gente" é a segunda variante mais frequente e que seu uso está condicionado por fatores sociais (tipo de escola) e fatores linguísticos (posição do acento, tempo verbal, tipo de conjugação verbal e contexto fonológico seguinte). As variáveis selecionadas, por um lado, apontam os contextos mais frequentes de emersão de "a gente" e por outro que estamos diante de outra regra gramatical para indicar a $1^{\mathrm{a}}$ pessoa do plural.
\end{abstract}

Palavras-chave: Variação linguística. A gente. Língua escrita. Escola.

\begin{abstract}
There are an increasing number of studies that have investigated the processes of linguistic variation. Results attest that linguistic uses are conditioned by internal and social restrictions. We aim to describe and analyze the behavior of the pronominal expression "we", in the light of the Theory of Variation (LABOV, 1966; 2008[1972) in written texts, produced by two public schools. The corpus consists of 91 texts (literary and chronic memories), and is stratified by gender, educational level, age group, textual / discursive genre, type of school and linguistic variables. The methodology followed the steps of the Labovian technique and for statistical treatment, after extracting the occurrences and coding, the Goldvarb X Program package was used (SANKOFF, TAGLIAMONTE; SMITH, 2005). The results obtained demonstrate that the pronominal expression "we" is the second most frequent variant and that its linguistic use is conditioned by social factors (school type) and linguistic factors (accent position, verbal tense, type of conjugation verbal and following phonological context). The selected variables, on the one hand, point out mathematically the most frequent contexts of emergence of the variant "we" and on the other that we are facing another grammatical rule to indicate the 1st person of the plural in Brazilian Portuguese.
\end{abstract}

Keywords: Linguistic variation. We. Written language. School.

\footnotetext{
${ }^{1}$ Secretaria de Estado da Educação, da Cultura, do Esporte e do Lazer, Montanhas, RN, Brasil. Endereço eletrônico: josenildo.bfreire@hotmail.com.
} 


\section{Introdução}

A visão laboviana de língua postula a existência de variação inerente ao sistema. Os usos linguísticos são condicionados por restrições não só estruturais, mas também por fatores sociais (externos). E que, mesmo ocorrendo a variação, os resultados são variantes que possuem plenitude formal (SAPIR, 1924) e potencial semiótico (FARACO; ZILLES, 2017). Classicamente, os estudos variacionistas têm sido realizados sob as perspectivas da Linguística Histórica, da Dialetologia e das Sociolinguísticas (Quantitativa, Qualitativa e Histórica). Este trabalho filia-se a abordagem quantitativa.

Um exemplo desse processo de variação pode ser visto nos usos referentes à alternância pronominal entre nós e a expressão a gente no português do Brasil (doravante, PB). Diversos estudos linguísticos têm evidenciado que estamos diante de uma reorganização do quadro canônico pronominal no PB, possibilitando o surgimento de uma nova variante no sistema, ao lado do pronome nós há a expressão pronominal a gente, assim, saindo de uma regra categórica, com uma só forma para uma regra variável.

O estudo desse processo sociolinguístico se reviste ainda de maior importância quando consideramos o trabalho de Lopes (2004) que toma a variação de a gente estuda/nós estudamos como casos de mudança linguística em curso e não apenas um evento de variação linguística. A introdução da expressão pronominal a gente, quanto também do item lexical você, na função de sujeito, desencadearam a reorganização do sistema de concordância verbal do PB.

A variante canônica para fazer referência à primeira pessoa do plural, em português, é a forma pronominal "nós" ou até mesmo a sua co-ocorrente " $\varnothing$ ". Contudo, as pesquisas descritas sobre o PB atestam uma língua que se distancia do que tradicionalmente estabelecem as gramáticas tradicionais, sobretudo, com a emersão da expressão pronominal a gente, tanto para se referir a terceira pessoa do singular como também a primeira pessoa do plural.

Basso (2019, p. 75-76) afirma que a entrada de a gente no quadro do sistema verbal do PB não é um "erro" por dois motivos: (i) ela ocorre frequentemente em diversas partes do Brasil - seria ao menos um milagre que um mesmo e idêntico erro acontecesse em todo território nacional e (ii) sempre ocorre igual, ou seja, não temos "agente comi" ou "a gente como", ou ainda "a gente comeram", mas sim "a gente come" ou "a gente comemos". Isto é, a expressão a gente está inserida no quadro pronominal do PB sempre se referindo à terceira pessoa do singular ou à primeira pessoa do plural.

Segundo Lopes (1998) e Freitag et al (2016), há no português atual uma sistemática preferência pela expressão a gente - forma típica para uso de terceira pessoa do singular e a 
primeira pessoa do plural - para se referir à primeira pessoa do plural, ocorrendo, dessa forma, processos variáveis no PB relacionados a esse uso da língua.

Viana e Lopes (2015) já atestam que as investigações linguísticas envolvendo a variação entre "nós" e "a gente" caracterizam esse processo como mudança linguística que vem se verificando no falar brasileiro. Assim, nesse texto, as referidas autoras realizam um mapeamento sociolinguístico das diversas pesquisas já empreendidas nas diversas regiões do Brasil e chegam à conclusão de que o fenômeno em discussão está em estágio bem avançado, mais do que o imaginado, havendo sinais claros de que também se trata de variação diatópica. Essa última afirmação é também corroborada pelos estudos de Freitag et al (2016), no falar do Rio Grande do Sul.

Tanto os usos linguísticos quanto os falantes podem sofrer avaliação negativa, sansão social e preconceito linguístico. Contudo, ainda segundo Viana e Lopes (2015), a expressão a gente cada vez mais recebe menos avaliação negativa da comunidade e dessa maneira figura nos mais diversos gêneros textuais/discursivos que circulam em diferentes esferas comunicativas, contornando desde textos mais informais aos mais monitorados.

A literatura específica (ZILLES, 2005; SANTOS, 2014; MENDONÇA, 2016; dentre outros) atesta que a expressão a gente é favorecida na fala de informantes do sexo feminino. Freitag et al (2016), por exemplo, verificaram em seus dados que o percentual de ocorrência dessa variante linguística em detrimento da forma pronominal canônica alcança índices de $82.9 \%$ em todo o corpus pesquisado e que há predominância de a gente em todos os contextos analisados (variável tipo de coleta), ou seja, em entrevistas e em situações de interação.

Mesmo com os diversos achados das pesquisas sociolinguísticas, em que se tomam por base a produção acadêmica dos últimos 30 anos, as gramáticas tradicionais ainda não captam essa variação e tampouco reconhecem o estatuto pronominal da expressão a gente. Realidade não só verificada com esse processo variável, mas, também, com outros fenômenos sociolinguísticos envolvendo o PB.

Os processos de variação linguística podem ser verificados tanto na língua falada quanto na língua escrita. Neste trabalho, partimos da hipótese de que tanto a língua falada quando a língua escrita comporta variação linguística (VIEIRA; FARACO, 2019).

A investigação da variação linguística na modalidade escrita da língua cobre uma lacuna ainda aberta no interior das pesquisas sociodialetais que tradicionalmente abordam a modalidade oral da língua. Assim, mesmo reconhecendo que a modalidade escrita da língua constitui um estilo mais monitorado da língua, em seus usos em diferentes gêneros 
textuais/discursivos, podemos verificar a emersão de usos sociolinguísticos variados. O presente trabalho insere-se nessa abordagem de trabalho.

Assim, objetivamos descrever e analisar o uso da expressão pronominal a gente em dois gêneros textuais/discursivos diferentes, produzidos por alunos de duas escolas públicas do interior do Rio Grande do Norte, à luz da teoria da Variação Linguística de base laboviana (LABOV, 1963; 1966; 2008 [1972]).

Para alcançar o objetivo geral deste trabalho, assim está organizado o artigo: na primeira seção, situamos a perspectiva teórico-metodológica que assumimos como ancorarem e fundamentação; na segunda, apresentamos o corpus e a metodologia; na terceira seção, descrevemos e analisamos os dados e por fim assinalamos algumas considerações finais.

\section{Fundamentação teórica}

Os estudos voltados para descrição e análise dos usos sociais das línguas surgiram, na Linguística, como uma reação às abordagens estruturalistas e gerativistas que priorizam os aspectos formais da língua em detrimento dos elementos funcionais, discursivos, sociais, pragmáticos, por exemplo.

Contudo, a variação linguística é um fator inerente às línguas naturais e sempre despertou o interesse de muitos linguistas. Assim, desde a perspectiva neogramática, com Schuchardt (HORA, 2004), já se entendia, de forma ainda incipiente, que há condicionamento linguístico e variabilidade cultural na fala.

O postulado de que não há independência do conhecimento linguístico em relação ao uso, de fato, ocorreu com os pioneiros estudos sociolinguísticos de W. Labov que ainda na década de 1960 realizou estudos que enfocam a abordagem da linguagem no contexto social. Assim, investigou a centralização dos ditongos (ay) e (aw) e o apagamento do (r) no inglês vernacular falado, respectivamente -, em duas comunidades de fala, Martha's Vineyard e Nova York, evidenciando que o uso desses dois processos está, também, condicionado por restrições de natureza social.

Desde então, passou-se a compreender melhor que a existência de variantes linguísticas numa dada língua, além de ser um fenômeno recorrente não é um fato centrado num indivíduo, é também condicionado por restrições de natureza social e ao mesmo tempo demonstra-se estruturado, exibindo plenitude formal e suficiente potencial semiótico, como assinalamos anteriormente.

Neste sentido, qual é então a tarefa da Sociolinguística? Para Cezario e Votre (2008), a tarefa do pesquisador na área de Sociolinguística deve: 
[...] é entender quais são os principais fatores que motivam a variação linguística, e qual a importância de cada um desses fatores na configuração do quadro que se apresenta variável. O estudo procura verificar o grau de estabilidade de um fenômeno, se está em seu início, ou se completou uma trajetória que aponta para mudança (CEZARIO; VOTRE, 2008, p. 141, destaque dos autores).

Mollica (2004, p. 9), por sua vez, defende que a Sociolinguística "estuda a língua em uso no seio das comunidades de fala, voltando sua atenção para o tipo de investigação que correlaciona aspectos linguísticos e sociais". Neste sentido, para essa teoria de estudos sociodialetais, a variação é um processo estruturado (MARTELOTTA, 2011).

Outro ganho considerável da abordagem sociolinguística diz respeito ao fato de se compreender as formas alternativas da língua não como sinal de baixo desempenho cognitivo, mas como resultado dos usos reais da língua em uma comunidade de fala, evidenciando que aspectos sociolinguísticos podem ter impacto sobre as escolhas linguísticas dos falantes.

Os estudos sociolinguísticos, também, enriqueceram-se com a adoção de modelos matemáticos e computacionais como ferramentas de descrição e análise linguística. Por exemplo, Cedergren e Sankoff (1974) apresentam um modelo teórico-metodológico baseado em dados estatísticos e probabilísticos para dar suporte ao conceito de regra variável.

Assim, para Cedergren e Sankoff (1974, p. 333): "the option is subject to regular constraints reveled through patterns of covariation with elements of the linguistic environment and with non-language factors such as age, class and social context".

O modelo estatístico visa auxiliar o pesquisador na explicação do efeito de frequência de uma determinada regra variável, indicando os aspectos probabilísticos de uso da gramática dos falantes. A frequência, desse modo, constitui um fator de explicação do uso.

Podemos conferir essa realidade sociolinguística quando consideramos o fenômeno da variação da expressão pronominal a gente, sejam em dados da língua falada, sejam em amostras de língua escrita; por exemplo, além de constatarmos o comportamento variacionista dessa expressão, também, identificamos os fatores internos e os sociais que condicionam seu uso na comunidade de fala investigada, o que por um lado, nos possibilita identificar mecanismos para explicar sua funcionalidade sociolinguística, como por outro, permite conjecturar sobre seu processo como um processo de variação ou de mudança em curso.

$\mathrm{Na}$ seção seguinte, delineamos o percurso metodológico desta investigação sociolinguística. 


\section{Corpus e metodologia}

O corpus foi constituído de noventa e um textos narrativos, especificamente pertencentes aos gêneros textuais/discursivos memórias literárias e crônicas, produzidos por alunos de duas escolas da rede pública de ensino, sendo uma da esfera municipal e outra da esfera estadual. Os alunos cursavam do $6^{\circ}$ ao $9^{\circ}$ do Ensino Fundamental. Contudo, durante a coleta e codificação das ocorrências, doze textos foram retirados, pois não apresentaram nenhuma frase relacionada à variação entre nós e a gente.

A Escola 1 de número identificador pelo INEP (Instituto Nacional de Estudos e Pesquisas Educacionais) $\mathrm{n}^{\mathrm{o}} 24062200$ e, a Escola 2 código INEP 24062405, ambas são situadas na zona urbana, de duas cidades do interior do Estado do Rio Grande do Norte, respectivamente, Montanhas e Pedro Velho.

Os textos foram produzidos na disciplina de Língua Portuguesa/Produção de Textos, no ano letivo de 2017, sob a regência do autor deste trabalho, a partir do protocolo no qual os alunos participantes teriam que relatar/narrar uma viagem significativa e marcante que já haviam participado. A escolha desse gênero textual/discursivo deve-se ao fato de os gêneros textuais/discursivos, sendo entidades sócio-discursivas ou práticas sócio-históricas variáveis, podem permitir a emersão de variantes linguísticas de baixo prestígio social. Assim, partimos do pressuposto de que os gêneros textuais/discursivos eleitos para esta investigação constituem situações comunicativas favorecedoras do uso de formas linguísticas de baixo prestígio social.

Também podemos ponderar que esses gêneros textuais/discursivos escolhidos podem refletir o vernáculo (LABOV, 2008[1972]) dos seus produtores, isto é, o estilo em que há menos monitoração e desse modo favorece o uso de variantes de baixo prestígio sociolinguístico.

Em relação ao envelope de variação, controlamos as seguintes variáveis da variável dependentes: (i) pronome de $1^{\circ}$ pessoa + verbo correspondente no plural; (ii) pronome de $1^{\circ}$ pessoa + apagamento de morfema modo-temporal -mos; (iii) pronome de $1^{\circ}$ pessoa + apagamento de morfema de plural -s; (iv) expressão pronominal a gente + verbo no singular; (v) expressão pronominal a gente + verbo correspondente no plural; (vi) sintagma nominal + eu + verbo correspondente no plural; e (vii) sujeito não explícito.

Já no que diz respeito às variáveis independentes, consideramos: sociais: sexo dos informantes (masculino x feminino); idade (dividida em dois fatores: 11 a 14 anos; e 15 a 18 anos); ano escolar $\left(6^{\circ}, 7^{\circ}, 8^{\circ}\right.$ e $\left.9^{\circ}\right)$ e tipo de escola (estadual x municipal); e linguísticas: estrutura verbal (simples x composto); posição do acento (paroxítono x proparoxítono), tempo 
verbal simples (pretérito, presente e futuro), conjugação verbal $\left(1^{\mathrm{a}}, 2^{\mathrm{a}}\right.$ e $\left.3^{\mathrm{a}}\right)$ e contexto seguinte (vogal, consoante e pausa).

As ocorrências das variantes foram codificadas e submetidas ao pacote de programa do Goldvarb X (SANKOFF; TAGLIAMONTE; SMITH, 2005), o qual forneceu o peso relativo que foi tomado como parâmetro de aplicação ou não da regra variável analisada. Esse programa toma como medida de aplicação o valor de peso relativo que se aproxima de 1,00; e considera neutros os que se aproximam de 0,50 e desfavorecedores da aplicação da regra variável os que estiverem próximos de 0,00 .

Na seção posterior, realizamos a descrição e análise dos dados coletados.

\section{Descrição e análise dos dados}

Nosso estudo irá voltar-se para descrição e análise da alternância pronominal entre nós e a gente. Ressaltamos, desse modo, não faremos uma análise da variação da concordância verbal propriamente dita desse fenômeno.

Após a codificação e a submissão das ocorrências encontradas ao Pacote de Programa Goldvarb X (SANKOFF, TAGLIAMONTE; SMITH, 2005), os resultados da distribuição geral das variantes são descritos na tabela 1 .

Tabela 1 - Distribuição das variantes no corpus analisado

\begin{tabular}{|c|c|c|}
\hline VARIANTES & FREQUENCIA/PERCENTUAL & EXEMPLO \\
\hline Sujeito não explícito & $148 / 336=44.0 \%$ & Viajamos! \\
\hline $\begin{array}{l}\text { Pronome de } 1^{\circ} \text { pessoa }+ \\
\text { verbo correspondente no } \\
\text { plural }\end{array}$ & $61 / 336=18.2 \%$ & Nós fomos! \\
\hline $\begin{array}{l}\text { Expressão pronominal } a \\
\text { gente + verbo no singular }\end{array}$ & $62 / 336=18.5 \%$ & A gente jogou. \\
\hline $\begin{array}{l}\text { Sintagma nominal }+\mathrm{eu}+ \\
\text { verbo correspondente no } \\
\text { plural }\end{array}$ & $34 / 336=10.1 \%$ & Meus amigos e eu fomos... \\
\hline $\begin{array}{lcr}\text { Expressão } & \text { pronominal } a \\
\text { gente } & + & \text { verbo } \\
\text { correspondente no plural }\end{array}$ & $1 / 336=0.3 \%$ & A gente saímos! \\
\hline $\begin{array}{l}\text { Pronome de } 1^{\circ} \text { pessoa + } \\
\text { apagamento de morfemas } \\
\text { de plural -s ou morfema } \\
\text { modo-temporal -mos }\end{array}$ & $25 / 336=7.4 \%$ & Nós pulamo $\phi /$ Nós estuda $\phi$ \\
\hline $\begin{array}{l}\text { Sintagma nominal }+\mathrm{eu}+ \\
\text { verbo no singular }\end{array}$ & $5 / 336=1.5 \%$ & Meus irmãos e eu foi pular \\
\hline
\end{tabular}


Considerando os resultados encontrados e exibidos na tabela 1 e a noção de regra variável, podemos entender melhor o comportamento da expressão pronominal a gente nos textos produzidos.

A primeira constatação que podemos fazer é que há um processo de variação sociolinguístico em curso, em relação à alternância pronominal entre as formas de marcar a primeira pessoa do plural no PB, manifestado por meio de diferentes formas e processos, isto é, seja expressando o sujeito ou não, usando a expressão pronominal a gente, seja por meio de um processo fonológico (apagamento de -s), ou ainda por meio de outro processo, no caso, morfossintático: apagamento de morfema: -mos, por exemplo.

Os resultados da tabela 1 podem ser agrupados, em um primeiro momento, de acordo com o percentual encontrado para cada variante. Essa divisão não será a mesma adotada para a análise feita com o uso do Goldvarb X (SANKOFF, TAGLIAMONTE; SMITH, 2005). Esta é uma primeira análise geral dos dados encontrados que nos fornecerá uma visão panorâmica do fenômeno sociolinguístico em discussão. Assim: no primeiro grupo, podemos inserir as variantes que não são alvo de preconceito, sansão ou desconforto social, isto é: o uso de sujeito não explícito, a expressão a gente + verbo correspondente no singular, o pronome nós + verbo correspondente no plural e o sintagma nominal + eu + verbo correspondente; já no segundo grupo, podemos incluir as variantes que são estigmatizadas socialmente: nós + o apagamento de morfemas, sintagma nominal + eu + verbo no singular e a expressão pronominal a gente + verbo no plural. Esses achados apontam para a formalização de que no PB há normas linguísticas e não apenas uma norma, constituindo o que assinala Faraco (2019): “Uma língua é, então, um conjunto de variedades (e só assim pode ser definida) distribuída no espaço geográfico e social e no eixo do tempo" (FARACO, 2019, p. 35).

Também, ressaltamos que optamos nesta análise por agrupar em um único fator as ocorrências de pronome de $1^{\circ}$ pessoa + apagamento de morfemas de plural -s ou morfema modo-temporal -mos, mesmo reconhecendo que a queda do -s final não configura ausência de plural e que portanto os dois morfemas -s e -mos indicam número-pessoa, sobretudo porque a diferença de frequência entre esses dois morfemas, no corpus, foi mínima, as ocorrências envolvendo o morfema -mos foram no total de 12, enquanto que as de -s foram no total de 13 casos.

Outra observação importante diz respeito à variante inovadora, a expressão pronominal a gente: ela ocupa a segunda posição, com o percentual de $18.5 \%$, mesmo que ligeiramente superior ao uso da forma canônica: o emprego de nós + verbo correspondente, com $18.2 \%$. Assim, esses achados começam a apontar para uma pergunta: o uso crescente de 
a gente pode contribuir para a redução da frequência de nós e diminuição das formas verbais mos, - mo $\phi$ nos verbos correspondentes a este pronome?

Nos dados analisados, a variante de maior frequência foi a que o sujeito não é explicitado (44.0\%). Esse achado está em sintonia com o que postula Avelar (2017), ao assinalar que a norma-padrão tem preferência por sujeitos não explícitos (oculto), o que aponta para a afirmação de que o PB é uma língua de sujeito nulo.

Desse modo, a variante inovadora começa a ganhar espaço na luta sociolinguística das variantes. O tempo e outros fatores cognitivos, também, nos fornecerão elementos para confirmar se se trata apenas de um processo de variação ou de mudança linguística em curso.

A quarta posição é ocupada pela variante sintagma nominal + eu + verbo correspondente, com percentual de $10.1 \%$, tipo de construção sintática da língua que não é alvo da ideologia padrão, uma vez que há harmonia entre os elementos constitutivos da variante em discussão e o uso da forma verbal.

As outras variantes encontradas no corpus em análise (Nós + apagamento de morfemas, sintagma nominal + verbo no singular e a expressão a gente + verbo no plural) alcançam, respectivamente, os percentuais de $7.4 \%, 1.5 \%$ e $0.3 \%$. Essas variantes são as que gozam de menos prestígio social nas comunidades de fala, sendo, portanto, alvos da ideologia padrão.

Ainda queremos justificar a permanência da variante expressão pronominal a gente + verbo correspondente no plural que obteve apenas uma ocorrência. A retirada dessa ocorrência não traria prejuízo estatístico algum para a análise. Diversos estudos na literatura específica atestam essa proposição (SCHERRE; NARO; YACOVENCO, 2018; por exemplo), mas que linguisticamente é um fato importante, revelando uma realidade da língua em uso.

Esses achados da tabela 1, também, estão em sintonia com o que propõe Labov (2003), ao tratar de três tipos de regras gramaticais: categóricas (100\% dos casos), semicategóricas (95\% a 99\% dos casos) e variáveis (5\% a 94\% dos casos). Os usos das variantes consideradas inovadoras, neste estudo, estão incluídos na regra gramatical variável, o que pode demonstrar que "os falantes variam e procuram adequar seus enunciados às necessidades e características das interações em que se envolvem" (FARACO; ZILLES, 2017, p. 201).

Também, é possível reconhecer que há a existência de regras gramáticas distintas operando em uma mesma comunidade de fala, sobretudo, ao evidenciar que toda variante tem organização, não é deficiente, nem menos lógica e tem potencial para dizer o que é para se dizer. 
Nas subseções seguintes, descrevemos e analisamos as variáveis selecionadas como condicionadoras do uso da expressão pronominal a gente.

\section{Variáveis selecionadas}

\section{Variável social}

O Programa Goldvarb X (SANKOFF; TAGLIAMONTE; SMITH, 2005) selecionou apenas a variável tipo de escola das varáveis sociais controladas como condicionadora do uso da expressão pronominal a gente no corpus analisado. O resultado está exibido na tabela 2.

Tabela 2 - Efeito da variável tipo de escola

\begin{tabular}{ccc}
\hline FATORES & $\begin{array}{c}\text { APLICAÇÃO/TOTAL }= \\
\text { FREQUENCIA }\end{array}$ & PESO RELATIVO \\
\hline Estadual & $37 / 170=21.8 \%$ & 0.69 \\
Municipal & $25 / 166=15.1 \%$ & 0.30 \\
Total & $62 / 336=18.5 \%$ & \\
\hline
\end{tabular}

Input: 0.091 / Significância: 0.009/log likelihood: -114.276

Fonte: Freire (2019).

A tabela 2 indica que os alunos pertencentes à escola da rede estadual são os que mais realizam a forma pronominal a gente em detrimento dos alunos pertencentes à rede municipal. Tanto os índices de frequência quanto os de pesos relativos apontam nessa direção, sobretudo, ao considerarmos o índice de peso relativo de $(0,69)$, como um dado matematicamente favorecedor da aplicação da regra variável em estudo. Constituem-se exemplos dessa variável as ocorrências como em: (i) “... a gente foi para a festa... (Informante 02: feminino, $6^{\circ}$ Ano, 12 anos e Esc. Estadual” e (ii) “... lá a gente arrumou e...” (Informante 09: masculino, 6 Ano, 11 anos e Esc. Estadual.

Neste sentido, entendemos que os alunos da escola estadual analisada estão exibindo maior consciência quanto aos usos linguísticos envolvendo os processos de variação do quadro pronominal no $\mathrm{PB}$ de que os alunos oriundos da escola municipal. Os processos variacionistas envolvendo o sistema pronominal e de concordância verbal são um traço linguístico diferenciador de normas sociolinguísticas no PB, desse modo, requerem dos falantes maior atenção.

Esses resultados indicam algumas direções: cada comunidade de fala realmente tem sua gramática própria, visto que as duas comunidades de falas envolvidas neste trabalho são próximas, em termos territoriais, distantes apenas $10 \mathrm{~km}$ uma da outra, mas que apresentam diferente configuração sociolinguística quanto ao uso da expressão a gente, revelando que o conceito de comunidade de fala é pertinente e relevante nos estudos sociodialetais. Esses 
dados podem apontar para a existência de um provável processo de variação diatópica, tal como postulado por Freitag et al (2016), no falar do Rio Grande do Sul; e também evidenciam que no PB há padrões sociolinguísticos diferentes e não apenas uma norma linguística.

A confirmação dessa hipótese requer a aplicação de um teste de avaliação sociolinguística, o que ainda não realizamos, e passa a constituir um desdobramento desta investigação. Essa proposta pode ser enriquecida com a incorporação do texto de Zilles (2007) que enumera os principais resultados de pesquisas linguísticas acerca processo de gramaticalização de a gente no $\mathrm{PB}$, seu encaixamento linguístico e aspectos da avaliação social do uso dessa variante.

As outras variáveis sociais não foram selecionadas pelo Goldvarb X (SANKOFF, TAGLIAMONTE; SMITH, 2005) como condicionadoras do uso da expressão pronominal a gente no corpus analisado. Contudo, entendemos que mesmo assim podem lançar luzes nesse processo variacionista e pistas qualitativas para análise.

Por exemplo, em relação à variável sexo dos informantes, o uso da expressão a gente é mais frequente nos textos produzidos pelos informantes do sexo feminino, com percentual de 19.6\%, em detrimento de $16.7 \%$ alcançados pelos informantes do sexo masculino. Esse achado pode apontar para o lado inovador da escrita feminina que sai de uma regra categórica para uma regra variável.

Como já assinalamos anteriormente, estudos também realizados por Zilles (2005), Mendonça (2012) e Santos (2016), por exemplo, atestam que a expressão pronominal a gente é favorecida na fala de informantes do sexo feminino.

No que diz respeito à variável idade dos informantes, verificamos que a expressão pronominal a gente foi mais frequente na escrita dos informantes mais jovens (11-14 anos), com índice de $19.2 \%$, em oposição aos informantes do segundo fator (15-18 anos) com percentual de $16.5 \%$. Esse fato pode ser um indicador ou reflexo do início de uma possível mudança linguística. Esses resultados também estão em sintonia com os achados de Zilles (2007) que constatou o favorecimento da expressão pronominal a gente, em dados de Porto Alegre, entre informantes da faixa etária mais jovem.

O uso da variante a gente também ocorreu de forma mais frequente nos textos produzidos por alunos pertencentes aos anos escolares de $6^{\circ}$ ao $7^{\circ}$, com percentual de $20.1 \%$ de que na escrita produzida pelos alunos dos $8^{\circ}$ ao $9^{\circ}$, com índice de $10.3 \%$. Essa configuração sociolinguística pode indicar que os alunos dos anos finais do Ensino Fundamental estão demonstrando maior consciência linguística quanto aos usos formais da língua e ainda exibem uma escrita conservadora. 
Quanto aos gêneros textuais/discursivos analisados, a frequência maior de uso da expressão a gente se deu nas memórias literárias, com percentual de $20.1 \%$ em detrimento do gênero crônica que atingiu o percentual de $10.3 \%$, nos dados analisados. A predominância da forma linguística a gente nas memórias literárias pode estar relacionada ao fato de que esse gênero é um texto que marca e caracteriza as relações pessoais entre interlocutores conhecidos, indicando familiaridade e aproximação entre os interagentes. Assim como Neves (2012), entendemos que a crônica mesmo sendo um gênero do meio escrito que apresenta alto grau de coloquialidade (alto grau de contextualização, alto nível de engajamento, temática variada e simplicidade formal e vivacidade de estilo) favorece o uso de uma escrita mais conservadora.

\section{Variáveis linguísticas}

As variáveis linguísticas selecionadas como relevantes para o emprego da regra variável em discussão, pelo Goldvarb X (SANKOFF, TAGLIAMONTE; SMITH, 2005), foram, por ordem de relevância estatística: posição do acento, tempo verbal, tipo de conjugação verbal e contexto fonológico seguinte.

Os resultados encontrados para cada uma dessas variáveis serão descritos e analisados nas tabelas 3 a 6 , a seguir.

Tabela 3 - Efeito da variável posição do acento

\begin{tabular}{ccc}
\hline FATORES & $\begin{array}{c}\text { APLICAÇÃO/TOTAL }= \\
\text { FREQUENCIA }\end{array}$ & PESO RELATIVO \\
\hline Paroxítono & $35 / 204=17.2 \%$ & 0.60 \\
Proparoxítono & $1 / 71=1.4 \%$ & 0.03 \\
Oxítono & $26 / 61=42.6 \%$ & 0.90 \\
Total & $62 / 336=18.5 \%$ & \\
\hline
\end{tabular}

Input: 0.091 / Significância: 0.009/ likelihood: -114.276

Fonte: Freire (2019).

A tabela 3 demonstra a influência da posição do acento sobre o uso da expressão pronominal a gente: há maior probabilidade de realização quando os vocábulos têm, respectivamente, acento oxítono $(0,90)$ e paroxítono $(0,60)$ em detrimento do acento proparoxítono. Os índices de peso relativos atribuídos a esses fatores confirmam essa hipótese como também os percentuais de cada fator.

Nesta pesquisa, consideramos como exemplos dessa variável ocorrências como em: (i) “... 9:30 a gente entrou no ônibus...” (Informante 15: masculino, 60 Ano, 13 anos e Esc. 
Estadual) e (ii) “... quando a gente fosse para...” (Informante 09: masculino, $6^{\circ}$ Ano, 11 anos e Esc. Estadual).

O desfavorecimento do fator proparoxítono pode estar relacionado a exigência que há na concordância verbal, que ao se usar a variante nós é requerido o uso de morfemas específicos -mos ou até mesmo -s; fato que não ocorre com o uso da expressão pronominal a gente.

Tabela 4 - Efeito da variável tempo verbal

\begin{tabular}{ccc}
\hline FATORES & $\begin{array}{c}\text { APLICAÇÃO/TOTAL }= \\
\text { FREQUENCIA }\end{array}$ & PESO RELATIVO \\
\hline Presente & $22 / 173=12.7 \%$ & 0.30 \\
Passado & $40 / 163=24.5 \%$ & 0.70 \\
Total & $62 / 336=18.5 \%$ & \\
\hline
\end{tabular}

Input: 0.091 / Significância: 0.009/ likelihood: -114.276

Fonte: Freire (2019).

A tabela 4 apresenta os resultados do efeito da variável tempo verbal sobre o uso da expressão pronominal a gente. Percebemos que o tempo passado é matematicamente favorecer da aplicação da regra variável em análise do que o tempo presente, este com índice de peso relativo inibidor da aplicação da regra $(0,30)$ e com percentual de frequência também desfavorecedor.

Constituem exemplos dessa variável os usos em: (i) “... a gente jogou vôlei...” (Informante 30: feminino, $7^{\circ}$ Ano, 13 anos e Esc. Estadual) e (ii) “...7:30 a gente chegou lá...” (Informante 43: feminino, $8^{\circ}$ Ano, 15 anos e Esc. Estadual).

O favorecimento desse fator "tempo passado" está relacionado aos gêneros textuais/discursivos que compõem o corpus analisado. Os dois gêneros textuais/discursivos produzidos são predominantemente narrativos, transitando necessariamente pelo passado, mesmo que os locutores narrem suas histórias no presente e reportam-se ao passado.

Em uma análise posterior, pode-se verificar o alcance e o efeito dessa variável subdividindo-a em dois fatores: passado perfeito e passado imperfeito e, assim, identificar outros aspectos dessa variável.

Tabela 5 - Efeito da variável conjugação verbal

\begin{tabular}{ccc}
\hline FATORES & $\begin{array}{c}\text { APLICAÇÃO/TOTAL }= \\
\text { FREQUENCIA }\end{array}$ & PESO RELATIVO \\
\hline $\mathbf{1}^{\mathbf{a}}$ Conjugação & $41 / 206=19.9 \%$ & 0.53 \\
$\mathbf{2}^{\mathbf{a}}$ Conjugação & $14 / 79=17.7 \%$ & 0.61 \\
$\mathbf{3}^{\mathbf{a}}$ Conjugação & $7 / 51=13.7 \%$ & 0.21 \\
Total & $62 / 336=18.5 \%$ & \\
\hline
\end{tabular}


Input: 0.091 / Significância: 0.009/ likelihood: -114.276

Fonte: Freire (2019).

A tabela 5 apresenta o efeito da variável tipo de conjugação verbal sobre o uso da expressão pronominal a gente no corpus analisado. De acordo com a tabela 5 , o uso da expressão pronominal a gente é favorecido pelos fatores segunda conjugação, com peso relativo de $(0,61)$ e, levemente, pela primeira conjugação, com índice de $(0,53)$, em detrimento do fator terceira conjugação com percentual inibidor da aplicação da referida regra variável em discussão.

As ocorrências dessa variável podem ser ilustradas com os exemplos: (i) “... depois a gente fez estrelinhas e...” (Informante 07: feminino, 6º Ano, 15 anos e Esc. Estadual (ii) “...na escola a gente lanchou e...” (Informante 16: feminino, $6^{\circ}$ Ano, 11 anos e Esc. Municipal).

Entendemos que há uma possível interferência da quantidade de verbos que pertencem às conjugações selecionadas favorecendo a aplicação da regra variável em discussão.

Tabela 6 - Efeito da variável contexto fonológico seguinte

\begin{tabular}{ccc}
\hline FATORES & $\begin{array}{c}\text { APLICAÇÃO/TOTAL }= \\
\text { FREQUENCIA }\end{array}$ & PESO RELATIVO \\
\hline Consoante & $50 / 209=23.9 \%$ & 0.60 \\
Vogal & $11 / 109=10.1 \%$ & 0.35 \\
Pausa & $1 / 18=5.6 \%$ & 0.20 \\
Total & $62 / 336=18.5 \%$ & \\
\hline
\end{tabular}

Input: 0.091 / Significância: 0.009/ likelihood: -114.276

Fonte: Freire (2019).

A tabela 6 apresenta e descreve os efeitos da variável contexto fonológico seguinte sobre o uso da expressão pronominal a gente. $\mathrm{O}$ fator consoante é favorecedor da aplicação da regra variável estudada com índice de (0.60) e também de acordo com a frequência desse fator, em oposição aos fatores vogal e pausa que recebem percentuais desfavorecedores.

São exemplos da ocorrência dessa variável, nos dados analisados, os exemplos em: (i) “...em outubro a gente começou a dar..." (Informante 08: feminino, 6 $6^{\circ}$ Ano, 12 anos e Esc. Estadual) e “...no carnaval a gente vai pra..." (Informante 09: masculino, 60 Ano, 11 anos e Esc. Estadual).

Atribuímos o favorecimento do fator consoante sobre os demais fatores ao fato de ser o mais frequente no corpus.

A seguir, expomos as considerações finais deste trabalho. 


\section{Considerações finais}

Neste trabalho, descrevemos e analisamos à luz da Teoria da Variação o comportamento sociolinguístico da expressão pronominal a gente em textos escritos por alunos da rede pública de ensino. Assim, após verificar o comportamento variável da expressão pronominal a gente, a amostra analisada evidencia que há uma preferência pelo seu uso, como a segunda variante para se referir a primeira pessoa do plural no PB.

Os resultados mesmo que ainda dentro de uma pequena amostra são bastante significativos. Primeiro, constatamos que estamos diante de outra regra gramatical para indicar a primeira pessoa do plural, no PB: a expressão pronominal a gente, realidade também atesta por outros estudos variacionistas (FREITAG et al., 2006; FREIRE, 2019, por exemplo); segundo, as variáveis selecionadas tanto a social quanto as linguísticas indicam matematicamente os contextos mais frequentes que permitem a emersão de uso dessa variante linguística; terceiro, constatado o uso dessa variante pelos alunos, a escola precisa dar um tratamento didático adequado à expressão pronominal a gente. Essa constatação constitui um desdobramento deste trabalho.

Diversos estudos têm evidenciado que no PB está ocorrendo a reorganização do quadro pronominal e da concordância verbal (FARACO, 2019), sobretudo pela introdução da expressão pronominal a gente. Nossos resultados corroboram com essa tese e também chamam a atenção para realização de práticas de ensino-aprendizagem baseada na descrição e na análise linguística e não apenas nos paradigmas propostos pela Gramática Tradicional.

Como possíveis desdobramentos dessa investigação, apontamos (i) a necessidade de aplicação de testes de avalição e percepção sociolinguística quanto às variantes encontradas e seus possíveis usos sociolinguísticos, o que pode desembocar na definição/confronto de comunidade de fala, a qual requer o compartilhamento de atitudes linguísticas quanto a determinados usos da língua; e (ii) a ampliação de amostras que permitirá não só estabelecer generalizações, mas também especificações quanto aos usos sociais da alternância pronominal entre nós e a gente, em dados orais e/ou escritos/multimodais.

Também há limitações nesta investigação. Sobretudo relacionada à composição das amostras, visto que trabalhamos apenas com um corpus de língua escrita que por si só tem suas especificidades sociocognitivas. Uma possível alternativa será a descrição comparativa de entre corpora e sua ampliação. 


\section{Referências}

AVELAR, R. O. de. Saberes gramaticais: formas, normas e sentidos no espaço escolar. São Paulo: Parábola, 2017.

BASSO, R. M. Descrição do Português Brasileiro. São Paulo: Parábola, 2019.

CEDERGREN, H. J.; SANKOFF, D. Variable rules: performance as a statistical reflection of competence. Language, v. 50, n. 2, p. 332-335, 1974.

CEZARIO, M. M.; VOTRE, S. Sociolinguística. In: MARTELOTTA, M. E. (Org.). Manual de linguística. São Paulo: Contexto, 2008.

FARACO, C. A.; ZILLES, A. M. S. Para conhecer norma linguística. São Paulo: Parábola, 2017.

FARACO, C. A. História do Português. São Paulo: Parábola, 2019.

FREIRE, J. B. Concordância da $1^{\mathrm{a}}$ pessoa do plural: o que dizem os textos escolares?.

Primeira Escrita, v. 6, p. 157-168, 2019.

FREITAG, R. M. Ko.; SANTANA, C. C. de; ANDRADE, T. R. C. de; SOUSA, V. S. Avaliação e variação linguística: estereótipos, marcadores e indicadores em uma comunidade escolar. In: FREITAG, R. M. Ko.; SEVERO, C. G; GÖRSKI, E. M. (Orgs.). Sociolinguística e Política Linguística: Olhares Contemporâneos. São Paulo: Blucher, 2016. p. 139-160.

HORA, D. da. Estudos Sociolinguísticos - perfil de uma comunidade. João Pessoa: Pallotti, 2004.

LABOV, W. The social motivation of sound change. Word, n. 19, p. 273-307, 1963.

LABOV, W. The social stratification of English in New York. Washington, D.C.: Center for Applied Linguistics, 1966.

LABOV, W. Some sociolinguistic principles. In: PAULSTON, C. B.; TUCKER, G. R. (Eds.). Sociolinguistics: the essential readings. Oxford: Blackwell, 2003. p. 235-250.

LABOV, W. Padrões Sociolinguísticos. Trad. Marcos Bagno, Maria Marta Pereira Scherre e Carolina Rodrigues Cardoso. São Paulo, Parábola, [1972] 2008.

LOPES, C. R. S. Nós e a gente no português falado culto do Brasil. D.E.L.T.A, n. 14, v. 2, p. 405-422, 1998.

LOPES, C. R. dos S. A gramaticalização de a gente em português em tempo real e de curta duração: retenção e mudança na especificação dos traços intrínsecos. Fórum Linguístico, v. 4, n. 1, p. 47-80, 2004.

MARTELOTTA, M. E. Mudança linguística: uma abordagem baseada no uso. São Paulo: Cortez, 2011. 
MENDONÇA J. J. Variação na expressão da $1^{\mathbf{a}}$ pessoa do plural: indeterminação do sujeito e polidez. 2016. 102 f. Dissertação (Mestrado em Letras) - Programa de PósGraduação em Letras, Universidade Federal de Sergipe, Sergipe, 2016.

MOLLICA, M. C. Fundamentação teórica: conceituação e delimitação. In: MOLLICA, M. C.; BRAGA, M. L. (Orgs.). Introdução à Sociolinguística: o tratamento da variação. $2^{\mathrm{a}}$ ed. São Paulo: Contexto, 2004. p. 9-14.

NEVES, M. H. de M. A Gramática passada a limpo: conceitos, análises e parâmetros. São Paulo: Parábola Editorial, 2012.

SAPIR, E. O gramático e a língua. In: SAPIR, E. Linguística como ciência. Ensaios. Rio de Janeiro: Acadêmica, 1969 [1924]. p. 29-42.

SANTOS, K. C. Estratégias de polidez e a variação de nós vs. a gente na fala de discentes da Universidade Federal de Sergipe. 2014. 87 f. Dissertação (Mestrado em Letras) Programa de Pós-Graduação em Letras, Universidade Federal de Sergipe, Sergipe, 2014.

SANKOFF, D.; TAGLIAMONTE, S.; SMITH, E. Goldvarb X. Computer program. Department of Linguistics, University of Toronto, Canadá. Disponível em: http://individual.ca/tagliamonte/goldvarb/GV_index.htm. Acesso em: 14 ago. 2020.

SCHERRE, M. M. P.; NARO, A. J; YACOVENCO, L. C. Nós e a gente em quatro amostras do português brasileiro: revisitando a escala da saliência fônica. Diadorim, Rio de Janeiro, v. 20, n. 1, p. 420-450, 2018.

ZILLES, A. M. S. The Development of a New Pronoun: the Linguistic and Social Embedding of a gente in Brazilian Portuguese. Language Variation and Change, n. 17, v. 1, p. 19-53, 2005 .

ZILLES, A. M. S. O que a fala e a escrita nos dizem sobre a avaliação social do uso de a gente? Revista Letras de Hoje, Porto Alegre, v. 42, n. 2, p. 27-44, junho, 2007.

VIANNA, J. S.; LOPES, C. R. dos S. Variação dos pronomes "nós" e "a gente". In: MARTINS, M. A.; ABRAÇADO, J. (Orgs.). Mapeamento Sociolinguístico do Português brasileiro. São Paulo: Contexto, 2015.

VIEIRA, F. E.; FARACO, C. A. Escrever na universidade: fundamentos. São Paulo: Parábola, 2019.

\section{Sobre o autor}

Josenildo Barbosa Freire (Orcid iD: https://orcid.org/0000-0003-3637-471X)

Doutor e mestre em Linguística pela Universidade Federal da Paraíba (UFPB); especialista em Ensino-Aprendizagem de Língua Portuguesa pela Universidade Federal do Rio Grande do Norte (UFRN); graduado em Letras pela Universidade Estadual da Paraíba (UEPB). É professor de Língua Portuguesa da rede pública de Educação Básica no Estado do Rio Grande do Norte.

Recebido em setembro de 2020.

Aprovado em outubro de 2020. 